\title{
Histological studies on ontogenic development of lymphoid organs in Indian major carp, Catla catla
}

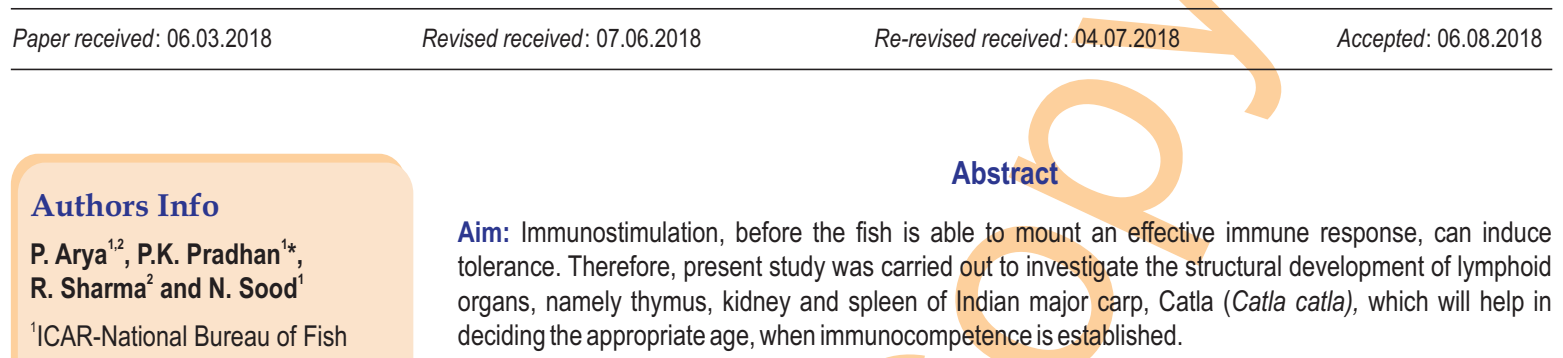

Genetic Resources,

Lucknow-226 002, India

${ }^{2}$ Department of Biosciences, Integral University,

Lucknow-226 026, India

*Corresponding Author Email : pradhanpk1@gmail.com

Edited by

Dr. Kamal Sharma

\section{Reviewed by}

Dr. Maisnam Manorama Devi

Dr. P. P. Chakrabarti
Methodology: In this study, ontogeny of the lymphoid organs of catla was studied from hatching up to 54 days post hatch (dph). For this, whole fish were fixed, processed and embedded in paraffin wax. Further, serial sections were cut, stained and observed under microscope.

Results: The thymus anlage appeared in the dorso-anterior part of the gill cavity at $1 \mathrm{dph}$. At $5 \mathrm{dph}$, an undifferentiated mass of stem cells was observed and by $8 \mathrm{dph}$, it appeared lymphoid. At $11 \mathrm{dph}$, clear dark and light zones of cells were observed. At $26 \mathrm{dph}$, Hassall's corpuscles were observed and no further changes were observed except increase in number of lymphoid cells till end of the sampling period. Kidney was observed as an undifferentiated mass of stem cells at $1 \mathrm{dph}$ with few renal tubules. At $5 \mathrm{dph}$, undifferentiated stem cells increased in number, and by $8 \mathrm{dph}$, few erythropoietic cells were observed. At 11 dph, lymphoid cells were present and by $17 \mathrm{dph}$, renal tubules started degenerating. At $26 \mathrm{dph}$, anterior kidney completely lacked excretory tissue and appeared lymphoid. Spleen was observed at 3 dph as an undifferentiated mass of stem cells, and at $8 \mathrm{dph}$, erythrocytes were seen. At $11 \mathrm{dph}$, spleen was heavily packed with erythrocytes, whereas at $20 \mathrm{dph}$, the number of erythrocytes decreased and lymphocytes were observed. Fully developed spleen was observed at 33 dph with presence of red and white pulp.

Interpretation: Thymus, head kidney and spleen were fully developed on $33 \mathrm{dph}$. The information generated in the present study would be helpful in deciding the appropriate age for vaccination

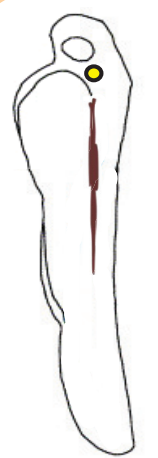
Thymus and Kidney
1 day post hatch

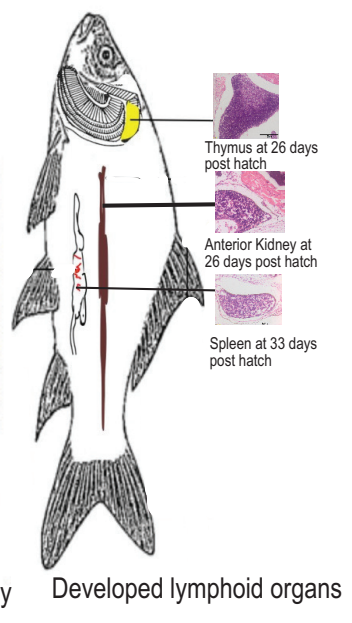

post hatch

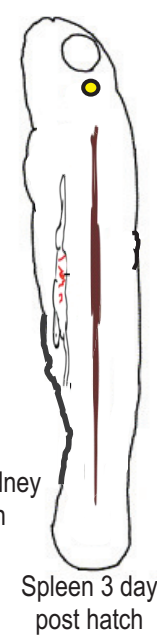

Key words: Catla catla, Histology, Lymphoid organs, Ontogeny

How to cite : Arya, P., P.K. Pradhan, R. Sharma and N. Sood: Histological studies on ontogenic development of lymphoid organs in Indian major carp, Catla catla. J. Environ. Biol., 40, 151-157 (2019). 


\section{Introduction}

India ranks second in aquaculture production in the world and freshwater aquaculture contributes over $95 \%$ of the total aquaculture production (Ayyappan, 2014; Mandal and Das, 2014). The three Indian major carps (IMC), namely rohu (Labeo rohita), catla (Catla catla) and mrigal (Cirrhinus mrigala) contribute to the extent of 70 to $75 \%$ of the total freshwater fish production (Ayyappan, 2014), and they are considered as the most popular table fishes having high market demand (Majeed et al., 2013). Among IMCs, catla is the fastest growing and attains 1$1.2 \mathrm{~kg}$ weight in the first year, compared to $700-800$ and $600-700 \mathrm{~g}$ attained by rohu and mrigal, respectively (Jena, 2006). This highlights the great commercial interest and aquaculture potential of this species. Larval rearing is considered to be one of the most critical and difficult stage in aquaculture practice and often associated with a high mortality rate during onset of feeding (Mohler et al., 2000). Although, catla has fecundity of 1-2 lakh kg-1, the recovery rate of spawn from egg is $60-70 \%$, whereas, recovery of fry from spawn is only $30-40 \%$, and fingerlings obtained from fry are only $30 \%$, which is normally lower than that of rohu and mrigal (Jena, 2006). Continuous efforts are devoted for the identification of nutritional and environmental requirements of fish larvae in order to reduce hatchery mortalities (Conceicao et al., 2010). However, very little information is available regarding physiology of the immune system, especially during the late larval and juvenile stages.

During early life stages, fishes are dependent on their innate defence mechanisms (Lange et al., 2006). Importantly, these innate defence mechanisms do not always suffice during encounter with pathogens. This emphasizes the need to establish adequate prophylactic counter measures like vaccination and use of probiotics. However, immunostimulation before the fish is able to mount an effective immune response, can induce tolerance resulting in lack of response to later stimulation (Rombout et al., 2005). Hence, it is important to know the appropriate age at which the larval immune system is developed, so that they can be effectively vaccinated. Although there are reports describing ontogenesis of important immune related organs and cells in many commercially important freshwater species like salmon (Salmo salar) (Ellis, 1977), rainbow trout (Salmo gairdneri) (Grace and Manning, 1980), common carp (Cyprinus carpio) (Press and Evenson, 1999) and for marine species like Atlantic cod (Gadus morhua) and sea bass (Dicentrarchus labrax) (Falk-Petersen, 2005), but scarce information is available on catla (Suresh and Ranganathan, 2008). Though, the basic developmental pattern of teleost fish is similar but direct comparison between species is difficult due to several biological factors, particularly those affecting early developmental stages (Patel et al., 2009). Therefore, the aim of this study was to describe the ontogeny of lymphoid organs (thymus, kidney and spleen) in catla through conventional histology technique during larval development. The information generated would help in deciding the appropriate age for vaccination.

\section{Materials and Methods}

Larvae used in the present study were procured from the Indian major carp hatchery of ICAR-National Bureau of Fish Genetic Resources, Lucknow. Briefly, catla broodfish were induced bred using Ovaprim, in the Chinese circular hatchery. The fertilized eggs were collected after 8-12 hrs of breeding and transferred to the hatching tank. The larvae hatched within 20-26 hrs of fertilization at $27-29^{\circ} \mathrm{C}$ water temperature. Forty eight hours after hatching, the larvae were transferred to cemented tanks $\left(14.2 \times 9.5 \times 1 \mathrm{~m}^{3}\right)$ and stocked at the density of 10 million $^{-1}{ }^{-1}$. Prior to stocking, the cemented tanks were provided with $10 \mathrm{~cm}$ soil base and filled with filtered pond water to a depth of $1.0 \mathrm{~m}$, and the level was maintained throughout the rearing period of 54 days by periodic filling. Fertilization of the tanks was carried out with recommended doses of $750 \mathrm{~kg} \mathrm{ha}^{-1}$ groundnut oil cake, $200 \mathrm{~kg} \mathrm{ha}$ ${ }^{1}$ cattle waste and $50 \mathrm{~kg} \mathrm{ha}^{-1}$ single super phosphate in split doses. Supplementary feed was provided at 400 and $800 \%$ of the initial biomass of spawn per day from 1 to 5 and 6 to 15 days, respectively. Thereafter, the larvae were fed at 10,8 and $6 \%$ of biomass per day from 15 to 30,30 to 45 and 45 to 54 days, respectively. During the rearing period, water temperature, $\mathrm{pH}$ and dissolved oxygen were in the range of $30-32^{\circ} \mathrm{C}, 7-8$ and $8-9$ ppm, respectively. Fish were held under natural photoperiod according to the rainy season of the year.

A random sample of 30 larvae was collected daily from hatching to 3 days post hatch (dph) and every third day from 5 to $26 \mathrm{dph}$ and every seventh day from 26 to $54 \mathrm{dph}$ from the mass rearing tanks. Larvae were euthanised with an overdose of tricaine methanesulphonate (MS-222, Sigma-Aldrich, St. Louis, MO, USA). Total length was measured in 10 randomly collected larvae using a scale to the nearest of $0.1 \mathrm{~cm}$. In addition, 20 larvae were fixed in $10 \%$ neutral-buffered formalin for histological analysis. Preserved samples were dehydrated in a graded series of ethanol, cleared in chloroform and embedded in paraffin. Serial sagittal sections (4-5 $\mu \mathrm{m}$ thick) were cut from each paraffin block using a rotary microtome (Leica RM 2135, Germany) and mounted on glass slides and air dried. Thereafter, tissue sections were deparaffinised with series of xylene, rehydrated and stained with haematoxylin and eosin (H\&E). All the stained tissue sections were permanently mounted in DPX and observed under a light microscope (Olympus BX 53, Japan) for general histomorphological observations.

\section{Results and Discussion}

In the present study, thymus anlage first appeared at 1 dph in the dorso-anterior part of the gill cavity as thickening of the pharyngeal epithelium next to the gill arches and was superficial in position (Fig. 1A). A similar superficial position has been reported in other species of fish (Grace and Manning, 1980). 


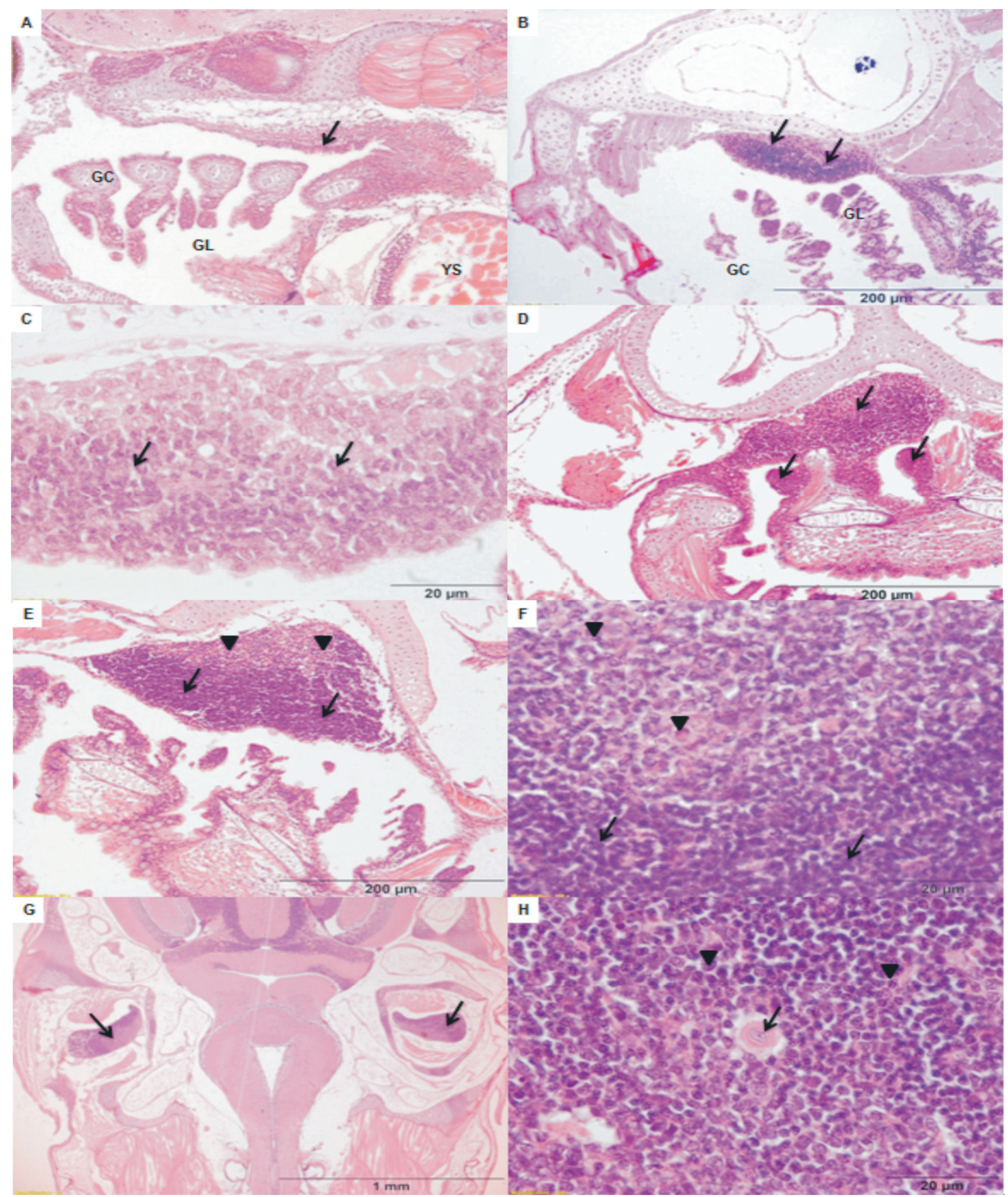

Fig. 1: Histological sections of thymus: (A) 1 dph larva showing the thymic anlage (arrow); (B) Undifferentiated mass of stem cells (arrows) distended into the brachial cavity occupying thymus at $5 \mathrm{dph}$; (C) Higher magnification of undifferentiated cells (arrows) at $5 \mathrm{dph}$; (D) Increase in number of darkly stained lymphocytes (arrows) at $8 \mathrm{dph}$. Please note many of lymphocytes are seen outside the thymic capsule; (E) Thymus showing lightly (arrow heads) and darkly stained zones (arrows) at $11 \mathrm{dph}$; (F) Higher magnification of $11 \mathrm{dph}$ thymus showing lightly (arrow heads) and darkly stained zones (arrows); (G) Paired thymus (arrows) on both sides of head above the gills at 23 dph and (H) Hassall's corpuscles (arrow) and developed lymphocytes (arrow heads) at 26 dph. GC-gill chamber; GL-gills and YS-yolk sac. 


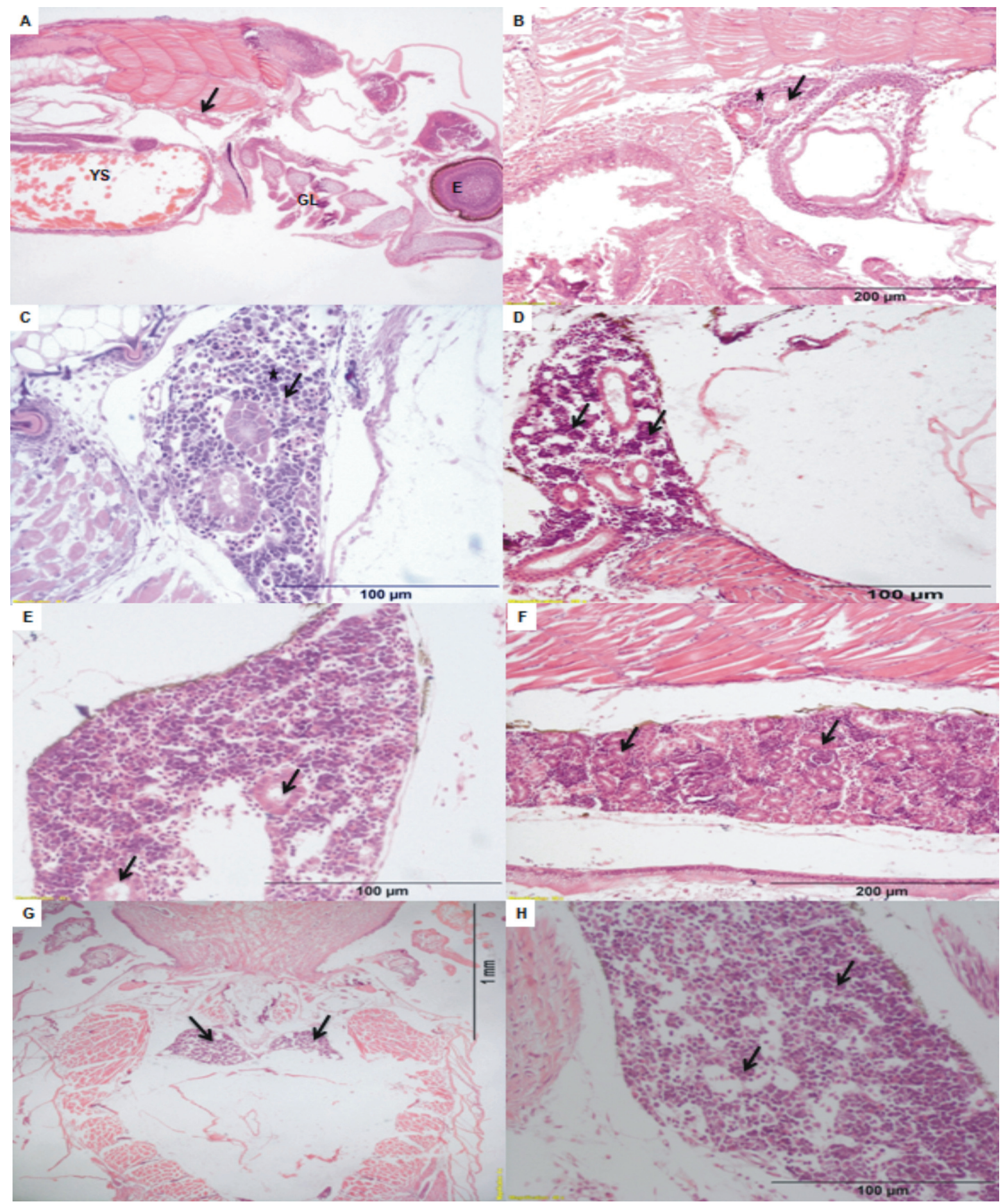

Fig. 2 : Histological structure of kidney development in catla: (A) Renal tubules (arrow) at dorso-posterior position of brancial cavity in $1 \mathrm{dph}$ larvae; (B) Undifferentiated cells (asterisk) around renal tubules (arrow) at $5 \mathrm{dph}$; (C) Many erythroid (arrow) and lymphoid cells (asterisk) were scattered at $8 \mathrm{dph}$; (D) Kidney with many smaller and darkly stained cells (arrows) at $11 \mathrm{dph}$; (E) Anterior kidney at $17 \mathrm{dph}$ with few renal tubules (arrow heads); (F) Posterior kidney showing many renal tubules (arrows) at $17 \mathrm{dph}$; (G) Paired kidney (arrows) as observed at $26 \mathrm{dph}$ and (H) Anterior kidney packed with lymphoid cells (arrows) at $26 \mathrm{dph}$. E-eye; GL-gills and YS-yolk sac. 

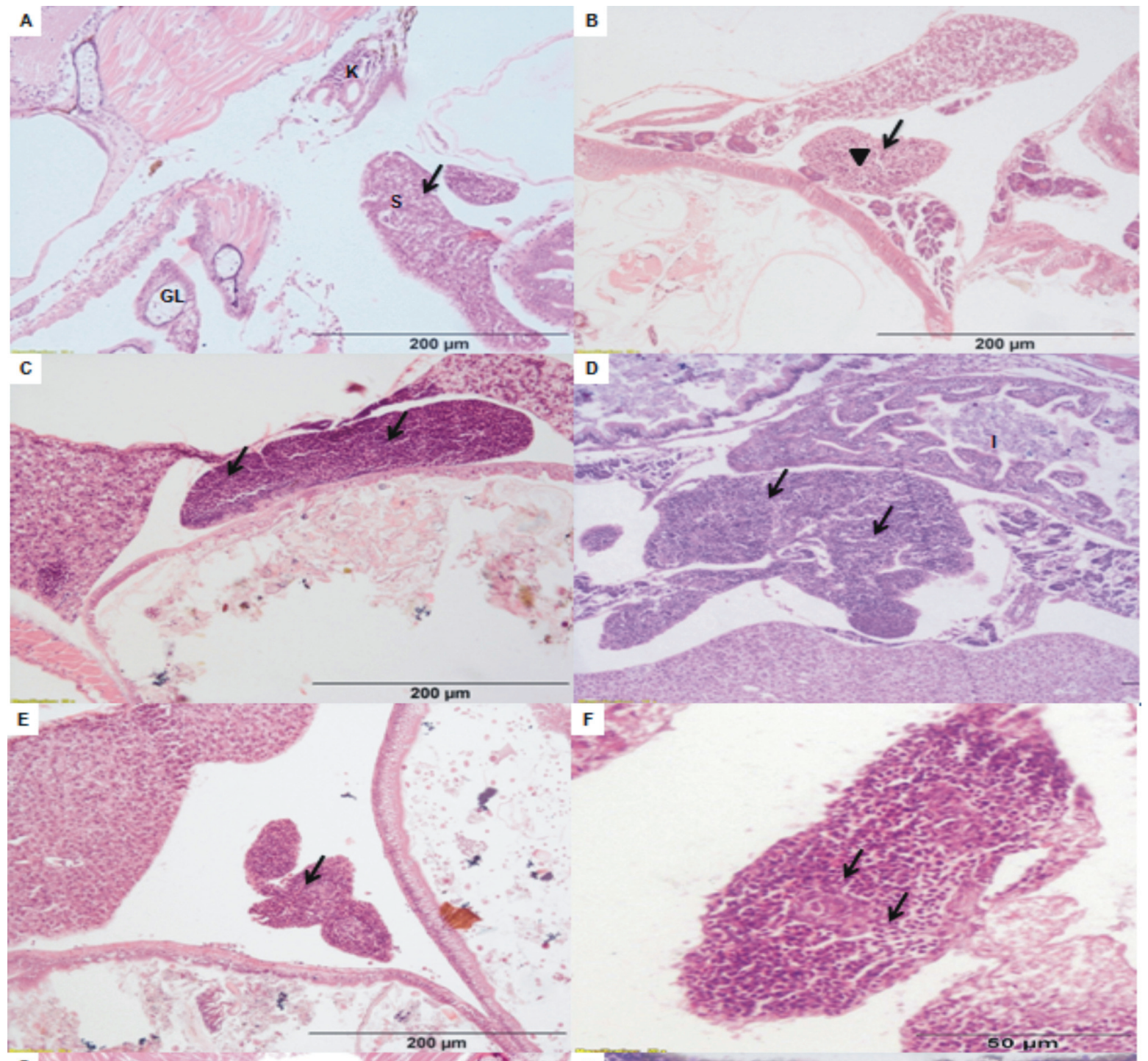

G

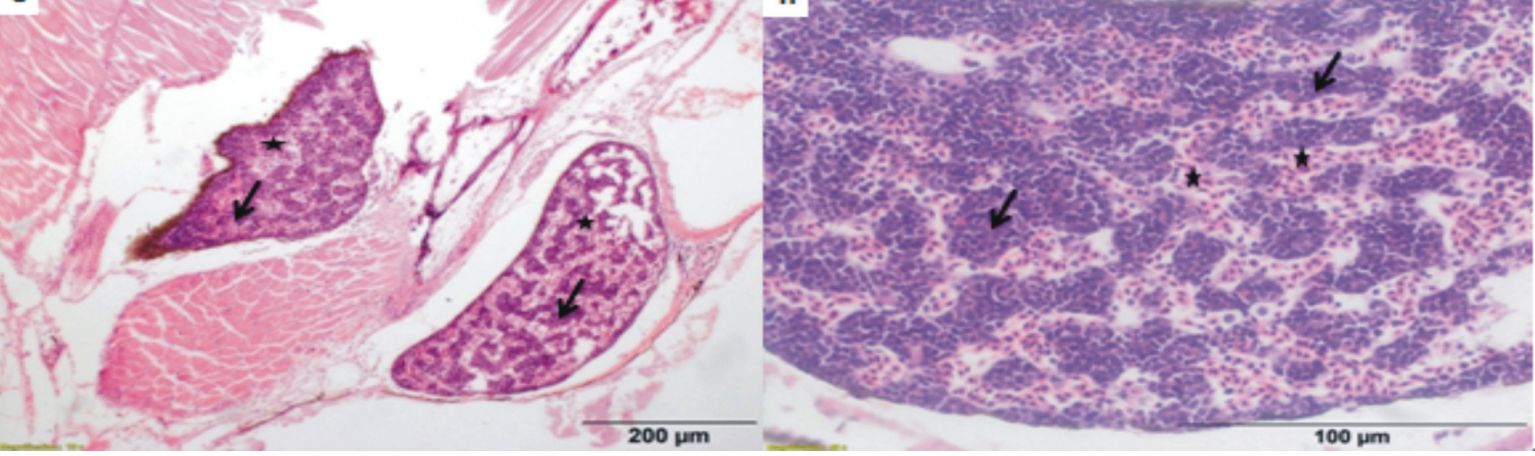

Fig. 3 : Spleen development in catla: (A) Undifferentiated mass of cells (arrow) at $3 \mathrm{dph}$; (B) Spleen (arrow) with haemopoietic cells (arrow head) at $8 \mathrm{dph}$; (C\& D) Spleen with lymphocytes (arrows) at 11 and $17 \mathrm{dph}$; (E \& F) Spleen at $20 \mathrm{dph}$ with decrease in number of erythrocytes and increase in darkly stained lymphocytes (arrows); (G) Well developed spleen at 33 dph showing white (arrows) and red pulp (asterisks) and (H) Higher magnification of spleen at 33 dph showing white (arrows) and red pulp (asterisks). GL-gills; l-intestine; K-anterior kidney and S-spleen. 
Thymus anlage has also been described in tilapia (Oreochromis mossambicus) at $1 \mathrm{dph}$ (Fishelson, 1995). At $5 \mathrm{dph}$, it was observed as an undifferentiated mass of stem cells, and the thymus distended into the branchial cavity (Fig. 1B, C). Similar observations have been reported in channel catfish (Ictalurus punctatus) (Petrie and Ainsworth, 2001). At 8 dph, smaller and darkly stained lymphocytes were observed which increased in number and many of these were seen outside the thymic capsule (Fig. 1D). Outside appearance of lymphoid cells has also been reported in carp (Botham and Manning, 1981). At 11 dph, thymus was differentiated into darkly and lightly staining zones (Fig. 1E, F). At $26 \mathrm{dph}$, thymus appeared fully differentiated, consisting smaller, rounded darkly stained cells and Hassall-like corpuscles (Fig. 1G, H). Corpuscles have also been observed in higher animals and in other teleost species of fish, such as queensland lungfish (Neoceratodus forsteri) (Mohammad et al., 2007), turbout (Psetta maxima) (Vigliano et al., 2011), cobia (Rachycentron canadum) (Klosterhoff et al., 2015) and tilapia (Oreochromis niloticus) (Cao et al., 2017). It is to be noted that in the present study, Hassall's corpuscles were observed at the later stages of development. Similar to our observations, it has been reported that Hassall's corpuscle did not exist at the early stage of thymus development, and were only formed through differentiation as development of thymus progressed (Romano et al., 1999). In the present study, no changes were observed in thymus after $26 \mathrm{dph}$, except increase in number of lymphoid cells till end of the sampling period of $54 \mathrm{dph}$, and no distinct division into cortical and medullary regions was observed. Similar to the present study, in common carp (Botham and Manning, 1981) and catla (Suresh and Ranganthan, 2008), no distinct cortex and medulla have been observed. However, in adult catla, distinct cortex and medulla have been reported (Chaudhary et al., 2012).

The head kidney is an important haematopoietic and lymphoid organ in fish. In the present study, kidney tubules were present as early at $1 \mathrm{dph}$ between the digestive tract and notochord (Fig. 2A). Similar observations have been reported in common carp and Asian sea bass (Lates calcarifer) at $2 \mathrm{dph}$ (Botham and Manning, 1981; Azad et al., 2009). At 5 dph, there was increase in intertubular tissue which consisted of unidentified haemopoietic stem cells (Fig. 2B). At $8 \mathrm{dph}$, foci of erythroid cells were observed among the blood sinuses of intertubular region and many lymphoid cells appeared scattered throughout the tissue (Fig. 2C). The proportion of lympho-haemopoietic tissue increased in the anterior part of kidney, whereas, in the posterior part, there were large numbers of tubules. At $11 \mathrm{dph}$, in the anterior part of the kidney, many smaller and more darkly stained cells were present (Fig. 2D). These may be differentiated cells of lymphoid line and indicate occurrence of active lymphopoiesis. At $17 \mathrm{dph}$, the tubules started degenerating in the anterior kidney and leucocyte aggregates remained as tightly packed clumps of white pulp. Similar to the present study, renal tubules degeneration has also been observed in crimson snapper (Lutjanus erythropterus Bloch 1790) (Cui et al., 2018). However, in contrast to our study, degeneration of renal tubules in the anterior kidney has not been reported in catla (Suresh and Ranganathan, 2008). In the present study, leucocyte aggregates remained as tightly packed clumps of white pulp but no distinct red pulp was seen. At $26 \mathrm{dph}$, kidney could be divided into two parts: anterior and posterior kidney. Anterior kidney lacked excretory tissue, whereas distinct sinuses and leucocyte pulp were dominant and posterior kidney was excretory with large number of renal tubules (Fig. 2G, H). Similar to the present study differentiation of kidney into anterior and posterior has been reported in catfish (Heteropneustes fossilis) (Kumar et al., 2016) and rock bream (Oplegnathus fasciatus) (Zhizhong et al., 2013).

Spleen serves as a erythrocyte reservoir and is a major secondary lymphoid organ in fish (Zexia et al., 2007). It plays an important role in immune system, similar to lymph nodes in mammals (Zapata et al., 1996). In the present study, spleen was identified at $3 \mathrm{dph}$ with undifferentiated mass of cells and was closely associated with pancreas and was the last lymphoid organ to develop (Fig. 3A). Similarly, spleen has been reported to develop after thymus and kidney in other fish species i.e., channel catfish ( $3 \mathrm{dph}$ ) (Petrie and Ainsworth, 2001) and Asian sea bass (2 dph) (Azad et al., 2009). At $8 \mathrm{dph}$, lightly staining haemopoietic cells were seen (Fig. 3B). At $11 \mathrm{dph}$, spleen increased in size and was more heavily packed with cells, most of which were erythrocytes and indicated erythropoietic nature of spleen (Fig. 3C). At $20 \mathrm{dph}$, number of erythrocytes decreased and lymphoblasts developed into small and darkly stained lymphocytes (Fig. 3E, F). Fully developed spleen was observed at $33 \mathrm{dph}$ with presence of red and white pulp, macrophages and ellipsoids (Fig. 3G, H). Similarly, red and white pulp have been observed in Asian sea bass (Azad et al., 2009) and rock bream (Zhizhong et al., 2013). However, in earlier studies with catla, no such clear differentiation of red and white pulp has been reported (Suresh and Ranganathan, 2008).

It is important to note that differences in the appearance and development of lymphoid organs can occur between the species and within the species, depending on the environment where the fish is reared (Patel et al., 2009). ). From the present study, it can be concluded that catla showed a histomorphologically well-differentiated thymus and kidney at 26 $\mathrm{dph}$ and spleen at $33 \mathrm{dph}$ which was observed in the larvae, of length $(1.9 \mathrm{~cm} \pm 0.04 \mathrm{~cm})$ and $(2.1 \mathrm{~cm} \pm 0.08 \mathrm{~cm})$, respectively. This information about the structural development of the immune organs will be helpful in deciding the timing of vaccination, and thus reducing mortality in larval rearing.

\section{Acknowledgments}

The authors are thankful to the Director, ICAR-National Bureau of Fish Genetic Resources, Lucknow for providing necessary facilities to carry out this work. The authors wish to express their sincere thanks to the anonymous reviewers and esteemed editor for their valuable suggestions which improved 
the manuscript, significantly. The first author is thankful to Integral University, Lucknow for Ph.D. registration (manuscript number IU/R\&D/2017-MCN000218). The first author is also thankful to ICAR-Consortium Research Platform on Vaccines and Diagnostics for providing the fellowship.

\section{References}

Ayyappan, S.: National Aquaculture Sector Overview, India. National Aquaculture Sector Overview Fact Sheets. In: FAO Fisheries and Aquaculture Department, Rome (2014). (http://www.fao.org/ fishery/countrysector/naso_india/en).

Azad, I.S., A.R. Thirunavukkarasu, M. Kailasam, R. Subburaj and J.J.S. Rajan: Ontogeny of lymphoid organs in the Asian Sea Bass (Lates calcarifer, Bloch). Asian Fish. Sci., 22, 901-913 (2009).

Botham, J.W. and M.J. Manning: The histogenesis of the lymphoid organs in the carp Cyprinus carpio L. and the ontogenetic development of allograft reactivity. J. Fish Biol., 19, 403-414 (1981).

Cao, J., Q. Chen, M. Lu, X. Hu and M. Wang: Histology and ultrastructure of the thymus during development in tilapia Oreochromis niloticus. J. Anat., 230, 720-733 (2017).

Chaudhary, D.K., N. Sood, P.K. Pradhan, N.K. Agarwal and G. Rathore: Production and characterization of a monoclonal antibody against putative T lymphocytes of Catla catla. In Vitro Cell Dev. Biol. Anim., 48, 483-492 (2012).

Conceicao, L.E.C., M. Yúfera, P. Makridis, S. Morais and M.T. Dinis: Live feeds for early stages of fish rearing. Aquacult. Res., 41, 613-640 (2010).

Cui, K., Z. Fu, D. Cheng, Q. Yang, Z. Ma, J.G. Qin and J. Hu: Development of immune functionality in larval and juvenile crimson snapper, Lutjanus erythropterus (Bloch 1790). Aquacult. Rep., 10, 1-7 (2018).

Ellis, A.E.: Ontogeny of the immune response in Salmo salar. Histogenesis of the lymphoid organs and appearance of membrane immunoglobulin and mixed leucocyte reactivity. In: Developmental Immunobiology (Eds.: J.B. Solomon and J.D. Horton), Elsevier/ North-Holland Biomedical Press, pp. 225-231 (1977).

Falk-Petersen, I.B.: Comparative organ differentiation during early life stages of marine fish. Fish Shellfish Immunol., 19, 397-412 (2005).

Fishelson, L.: Cytological and morphological ontogenesis and involution of the thymus in cichlid fishes (Cichlidae, Teleostei). J. Morphol., 223, 175-190 (1995).

Grace, M.F. and M.J. Manning: Histogenesis of the lymphoid organ in rainbow trout, Salmo gairdneri Rich. Dev. Comp. Immunol., 1836, 255-264 (1980).

Jena, J.K.: Cultured Aquatic Species Information Programme, Catla catla. In: FAO Fisheries and Aquaculture Department, Rome (2006). (http://www.fao.org/fishery/culturedspecies/Catla_ catla/en).

Klosterhoff, M.C., P.J. Joaber, R.V. Rodrigues, E.P. Gusmão, L.A. Sampaio, M.B. Tesser and L.A. Romano: Ontogenic development of kidney, thymus and spleen and phenotypic expression of CD3 and CD4 receptors on the lymphocytes of cobia (Rachycentron canadum). An. Acad. Bras. Ciênc., 87, 2111-2121 (2015).

Kumar, R., K.P. Joy and S.M. Singh: Morpho-histology of head kidney of female catfish Heteropneustes fossilis: seasonal variations in melano-macrophage centers, melanin contents and effects of lipopolysaccharide and dexamethasone on melanins. Fish Physiol. Biochem., 42, 1287-1306 (2016).

Lange, S., S.H. Bambir, A.W. Dodds, T. Bowden, I. Bricknell and S. Espelid: Complement component C3 transcription in Atlantic halibut (Hippoglossus hippoglossus L.) larvae. Fish Shellfish Immunol., 20, 285-294 (2006).

Majeed, S., K.S. Abdul, N. Nambi, G. Taju, N. Sundar Raj, N. Madan and A.S. Sahul Hameed: Establishment and characterization of permanent cell line from gill tissue of Labeo rohita (Hamilton) and its application in gene expression and toxicology. Cell Biol. Toxicol., 29, 59-73 (2013).

Mandal, A. and S.K. Das: Comparative evaluation of iso-nutritional mash and pellet feed under mixed culture conditions of Indian major carp rohu (Labeo rohita) and mrigal (Cirrhinus mrigala). Int. J. Res. App. Nat. Soc. Sci., 2, 125-134 (2014).

Mohammad, M.G., S. Chilmonczyk, D. Birch, S. Aladaileh, D. Raftos and J. Joss: Anatomy and cytology of the thymus in juvenile Australian lungfish, Neoceratodus forsteri. J. Anat., 211, 784-797 (2007).

Mohler, J.W., M.K. King and P.R. Farrell: Growth and survival of firstfeeding and fingerling Atlantic sturgeon under culture conditions. N. Am. J. Aquacult., 62, 174-183 (2000).

Patel, S., E. Sorhus, I.U. Fiksdal, P.G. Espedal, O. Bergh, O.M. Rodseth, H.C. Morton and A.H. Nerland: Ontogeny of lymphoid organs and development of IgM bearing cells in Atlantic halibut (Hippoglossus hippoglossus L.). Fish Shellfish Immunol., 26, 385-395 (2009).

Petrie-Hanson, L. and A.J. Ainsworth: Ontogeny of channel catfish lymphoid organs. Vet. Immunol. Immunopathol., 81, 113-117 (2001).

Press, C.M. and O. Evensen: The morphology of the immune system in teleost fishes. Fish Shellfish Immunol., 9, 309-318 (1999).

Romano, N., M. Fanelli, G. Maria Del Papa, G. Scapigliati and L. Mastrolia: Histological and cytological studies on the developing thymus of sharpsnout seabream, Diplodus puntazzo. J. Anat., 194, 39-50 (1999).

Rombout, J.H., H.B. Huttenhuis, S. Picchietti and G. Scapigliati: Phylogeny and ontogeny of fish leucocytes. Fish Shellfish Immunol., 19, 441-455 (2005).

Suresh, N. and L.S. Ranganathan: Ontogeny of lymphoid organsthymus, spleen and kidney in Catla catla (Hamilton). Indian J. Fish., 55, 317-322 (2008).

Vigliano, F.A., A.P. Losada, M. Castello, R. Bermúdez and M.I. Quiroga: Morphological and immunohistochemical characterisation of the thymus in juvenile turbot (Psetta maxima L.). Cell Tissue Res., 346, 407-416 (2011).

Zapata, A.G., A. Chiba and A. Varas: Cells and tissues of the immune system of Fish. In: The Fish Immune System: Organism, Pathogen and Environment. (Fish Physiology series) (Eds.: G. Iwama, and T. Nakanishi). San Diego, CA, US: Academic Press Inc., pp. 255287(1996).

Zexia, G., W. Weimin, Y. Yi, K. Abbas, L. Dapeng, Z. Guiwei and J. Diana: Morphological studies of peripheral blood cells of the Chinese sturgeon, Acipenser sinensis. Fish Physiol. Biochem., 33, 213-222 (2007).

Zhizhong, X., H. Tao, L. Jun and G. Tianxiang: Ontogeny of the immune system in rock bream Oplegnathus fasciatus. Chin. J. Oceanol. Limnol., 31, 1028-1035 (2013). 